\title{
Effect of wrist abduction on force applied and response time during touch screen mobile phone use
}

\author{
Imtiaz Ali Khan 'Kumar Prateek and Shahnawaz Mohsin \\ Department of Mechanical Engineering, Aligarh Muslim University, Aligarh (U.P.)202002, India.
}

\begin{abstract}
This study investigated the effect of wrist abduction on force applied and response time while performing the distinct tasks using touch screen mobile phone. For this study, a questionnaire was designed and subjects were asked to answer the questions on the basis of daily use of their touch screen mobile phones. On the basis of survey, the two most frequently used postures (one- handed and two handed operation of touch screen mobile phone) were selected for this study. For each case (one handed and two handed posture), three levels of wrist abduction i.e. $0^{0}$ (neutral posture), $10^{\circ}$, and $20^{\circ}$ were taken. Human performance as force applied and motoraction response time was recorded using oscilloscope. These observations were taken for both postures (one handed and two handed). The experimental results were analysed using ANOVA and SPSS software. The ANOVA result shows that wrist abduction angle for both postures (one- handed and two handed) has a significant effect on performance of touch screen mobile phone users. Analysis of results indicates that the two handed posture with wrist abduction $0^{\circ}$ offers optimum performance in this environment.
\end{abstract}

Keywords: Touch screen; Mobile phone; Wrist angle of abduction; Response time; Force applied; MANOVA

\section{INTRODUCTION}

At the beginning of mobile phone development, touch panel technology was frequently used in public places, and it has become popular in individuals' everyday lives. For example, touch panels are often used in museums or as exhibition navigation guides and to display or sell goods in department stores. After the successive launches of i-Phone mobile in 2007 and the i-Pad in 2010, touch panels have begun to be implemented in applications for personal use. Moreover, in 2013, 10\% of all population in the India own a touch screen mobile phone; almost thrice the 3.5\% figure from 2012. Given the popularity of the touch screen mobile phone, many studies have analyzed touch screen mobile phone usability, including studies comparing the performance of operating tasks, one- and twohand gestures, differently sized touch panels, different age groups, and the design considerations for touch-screen interfaces of mobile phones. With the convenience of touch screen mobile phones increasing their frequency and duration of use, the design characteristics of these phones give rise to concerns regarding their impact upon body mechanics and the musculoskeletal system. The nature of cell phone use may facilitate the potential for the development of musculoskeletal symptoms. With more and more people owning Smartphone and spending greater amounts of time texting, tweeting, emailing, e-reading and surfing the net, physiotherapists have seen a significant increase in mobile phone and hand-held device related injuries. In addition to the common overuse and posture related injuries, there is also the risk of acute injuries sustained from using mobile phones in at risk situations (requiring full attention), such as whilst driving or walking (particularly on uneven surfaces). It is important to be aware of the risks associated with using a mobile phone or hand-held device and to take healthy steps and safety measures to avoid potential injury.

In over $40 \%$ of our observations, a user was interacting with a mobile phone without inputting any data via key or screen. Figure 1.10 provides a visual breakdown of the data from our observations

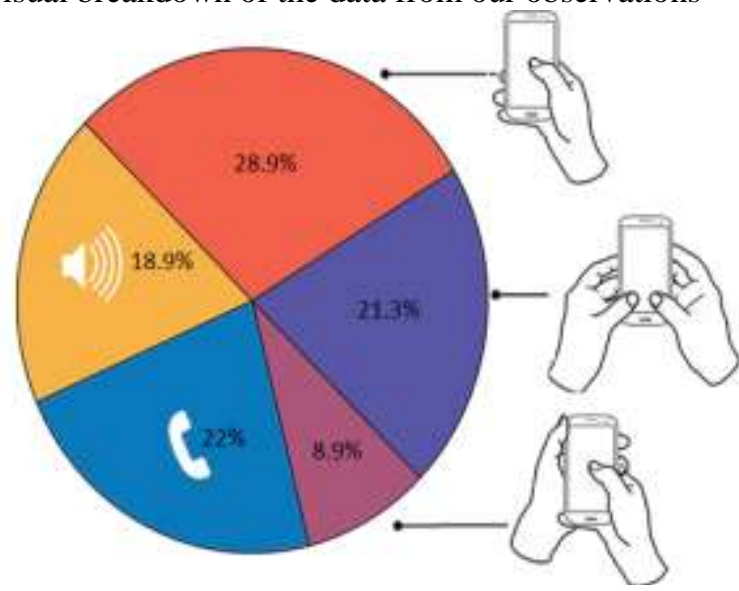

Figure-1.1 Summary of how people hold and interact with mobile phones (average usage time) 
Text entry is a fairly complex process, involving visual, tactile, motion, memory, learning, and other cognitive functions. Moreover, they belong to different levels of cognitive processing. The process of text entry is subject to the biomechanical constraints of the hand. Whether perceptual and cognitive concepts are suitable will dominantly affect the user's final performance, such as the response time and accuracy rate (Khan 2014a; Khan 2014b; Khan; 2014c; Khan 2014d; Khan and Asghar 2011; Khan and Asghar 2010). Therefore, if a new input method is to be designed, ergonomically designed operation and cognitive compatibility must be emphasized. According to Fitts' law concerning motion execution (Fitts, 1954), the keyboard layout should be arranged so that a finger travels the minimum distance necessary, allowing text entry efficiency to be improved. Realizing that the procedural memory has a subtle effect on users, many researchers have employed the transfer effect of learning to conduct relevant designs or studies (Carey, 2001; Jacob and Brad, 2008; Liang and Chang, 2009). Further, according to the findings regarding the stimulus-response compatibility effect (SRC effect), different hand postures will affect encoding patterns, which will vary with the relationship between visual stimulus and finger reaction (Ehrenstein et al., 1989; Khan et al., 2016; Lyons et al., 2004; Lyons et al., 2006). Input accuracy is critical to usability of mobile devices because people frequently use them for a variety of purposes such as personal information organizers, communicators, business appliances, and entertainment devices. High input accuracy enables users to finish their tasks quickly with few errors. In large touch screen environments such as automatic teller machines (ATMs) and information kiosks, a number of studies have been conducted to investigate usable touch key designs in terms of input accuracy. Understanding the typing postures of how users operate their mobile phones is crucial for developing new ways of interaction for text entry chording methods. Based on the observation by (Gold et al., 2012; Mackenzie, 2002; Mackenzie et al., 2009), three postures were found to occur most often by mobile phone users: holding the phone in one hand while using the index finger of another hand, holding the phone in the palm of the hand while using the thumb of the same hand, and using both hands to hold the phone and typing with both thumbs. Furthermore, this study tried to analyze the relationship between the typing postures and phones with different typing methods. Therefore, in this stage, the main purpose was to observe the postures when using phones with different typing methods. However, to determine which of the above three operating postures is suitable for the new chording methods can be compared via the two perspectives.
First, the operating posture needs to avoid the occlusion problem (fat finger problem) (Paul and Donna, 1994; Taeil et al., 2013; Wigdor., 2004) where the user's finger is too big and induces the error of touching neighbouring keys. Different hand anthropometries were measured for mobile phone and keypad design factors. Users with small hands might find it difficult to hold large mobile phones and users with large hands might find it difficult to hold small mobile phones, thus hand breadth was measured to test if it affects users' satisfaction towards mobile phone design factors. Hand breadth was measured at the distal ends of the metacarpal bones (the joints of index finger to the little finger) with the hand held straight and flat. Thumb length might affect users` reach ability of the keys whereas users with large thumbs might find it cumbersome keying in messages via the tiny keys (Balakrishnan and Yeow, 2008). Work-related Musculo-Skeletal Disorders (WMSDs) result in considerable costs to industry annually (Khan 2012). Various studies shows that risks of WMSDs are associated with certain jobs and certain work related factors compared with other population groups not exposed to risk factors. It is necessary to study repetitive exertions combined with tapping force for wrist abduction angle. So, the present study was designed to look at the effects of repetitive force exertion for abducted wrist postures.

\section{PROBLEM FORMULATION}

Based on the literature surveyed and responses through questionnaire, it was observed that the population was using touch screen mobile phone with single handed and two handed posture most of the time. Cradled form of holding was found to be least applied by users. So, we have selected one handed and two handed posture for our study and experimental investigations.

In the past, ergonomists studied the different postures while using the mobile phones that are suitable as well as comfortable to fit the body and the mind of the users. In the present study, it was observed that wrist angle of abduction is the important parameter that affect the performance of mobile users. In this work, two sets of study were undertaken on one handed and two handed postures. First study explored the effect of wrist angle of abduction $\left(0^{\circ}, 5^{\circ}\right.$ and $\left.10^{\circ}\right)$ on two parameters namely, response time and force applied and the second study explored the effect of three distinct tasks on the two parameters.

For developing an ergonomic database, the study has been formulated for both one hand and two hand postures as follows:

i. The angle of abduction has a significant effect on mobile users' performance in terms of response time. 
ii. The angle of abduction has a significant effect on mobile users' performance in terms of force applied.

\section{METHODOLOGY}

The stated hypothesis was tested through a set of experimental investigations. The experimental set up and its design are summarized as follows:

\subsection{Experimental set-up}

Experimental investigations were conducted in an isolated environment. The set up as shown in figure 3.1 comprised of the following sub-systems:

i. Touch screen mobile phone $(4.5$ " size touch screen)

ii. Oscilloscope

iii. Mica plate

iv. Touch sensors

v. Goniometer

vi. Lux meter

vii. Group of subjects

The 4.5" screen size of touch mobile phone used in our experiments was selected on the basis of users responses collected through questionnaire based survey. All the experimental observations were taken on Nokia Lumia 520 touch screen mobile phone with screen size 4.5". Performance of each subject was measured through oscilloscope on the basis of response variables namely, force applied and motor action time. A working platform comprising Mica plate and piezoelectric sensors attached with oscilloscope was used to hold the mobile phone and record the user performance for analysis. Goniometer was used to maintain the variable angle of Abduction. Lux meter was used to measure the light intensity of the isolated environment in which the experiments were performed. Group of subjects for the study was selected through stratified sampling.

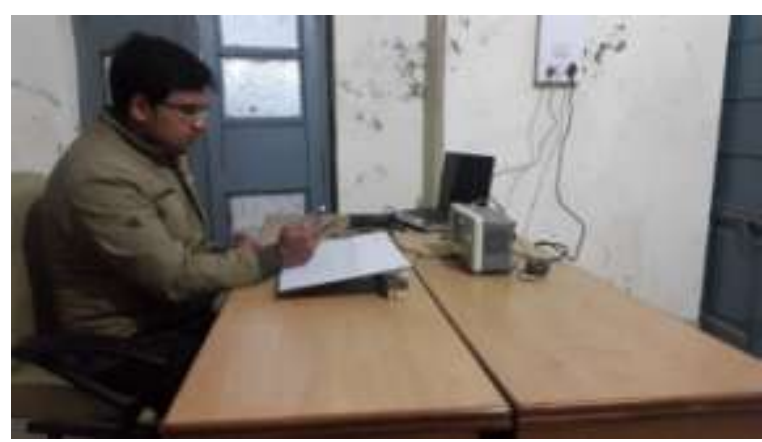

Figure-3.1 Experimental set-up

\subsection{Experiment design}

To evaluate the touch screen mobile phone users' performance, the response variable was taken as force applied and motor action response time. The three distinct tasks (T1, T2 and T3) and three wrist abduction angles $\left(0^{\circ}, 5^{\circ}\right.$ and $\left.10^{\circ}\right)$ were taken as fixed independent variables. The $6 \times 3$ combinations were considered to conduct the full experiment. The various tasks performed at different angle of abductions during the experiment are shown in figures 3.2 through 3.10 . The figure 3.11 shows the response time and applied force measurements through a two-channel oscilloscope.

A. Three selected tasks

i. Task 1(T1)(Bluetooth icon)

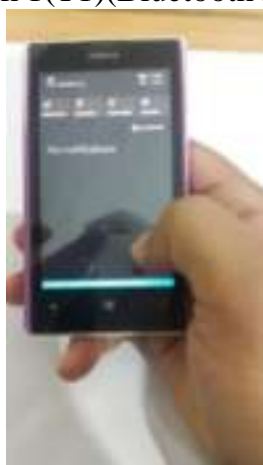

Figure-3.2 Initial position for Task (T1)

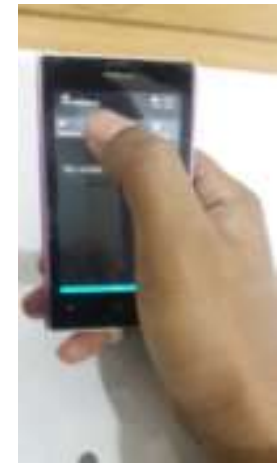

Figure-3.3 Final position for Task (T1)

ii. Task 2(T2)(Settings icon)

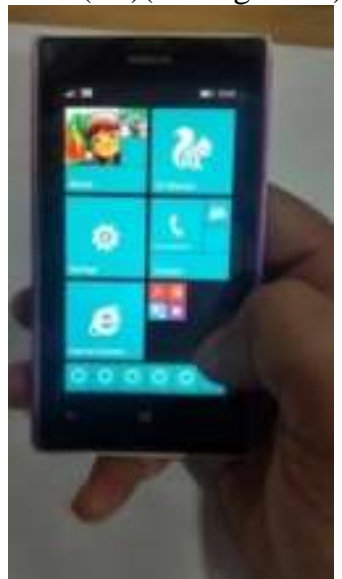

Figure-3.4 Initial position for Task (T2) 


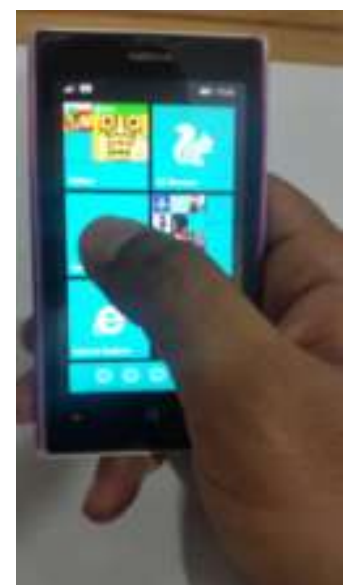

Figure-3.5 Final position for Task (T2)

iii. Task 3 (T3)(Contacts icon)

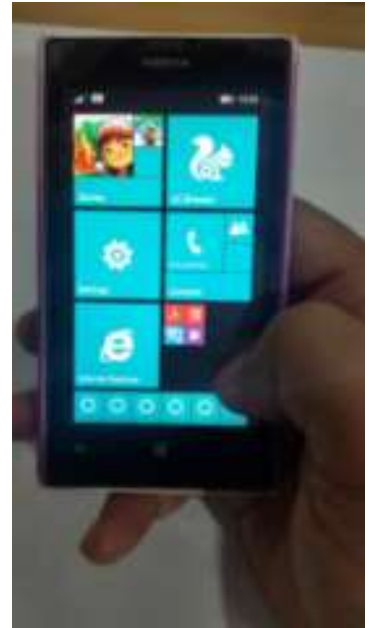

Figure-3.6 Initial position for Task (T3)

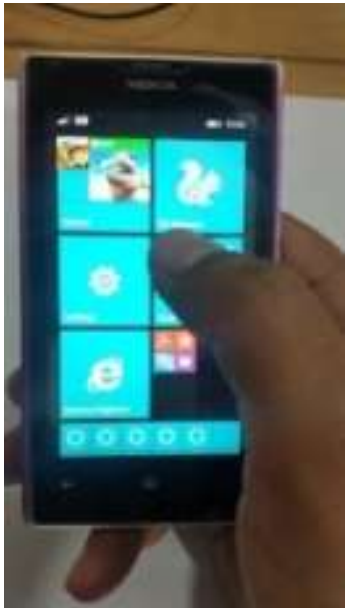

Figure-3.7 Final position for Task (T3)

B. Three selected wrist angle of abductions i. Wrist angle of abduction $\left(0^{\circ}\right)$

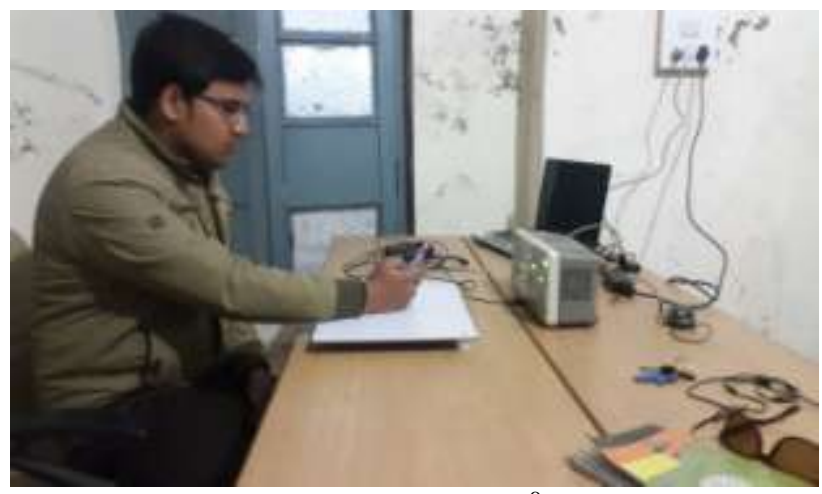

Figure-3.8 Experimental set up for $0^{\circ}$ wrist angle of abduction

ii. Wrist angle of abduction $\left(5^{\circ}\right)$

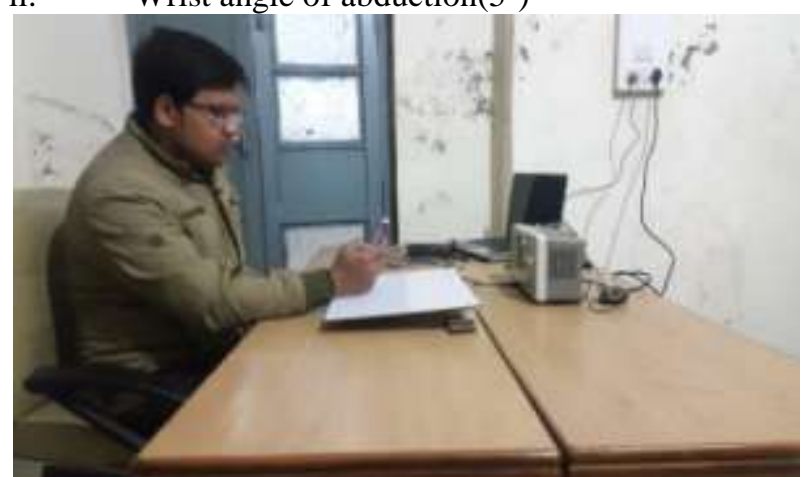

Figure-3.9 Experimental set up for $5^{\circ}$ wrist angle of abduction

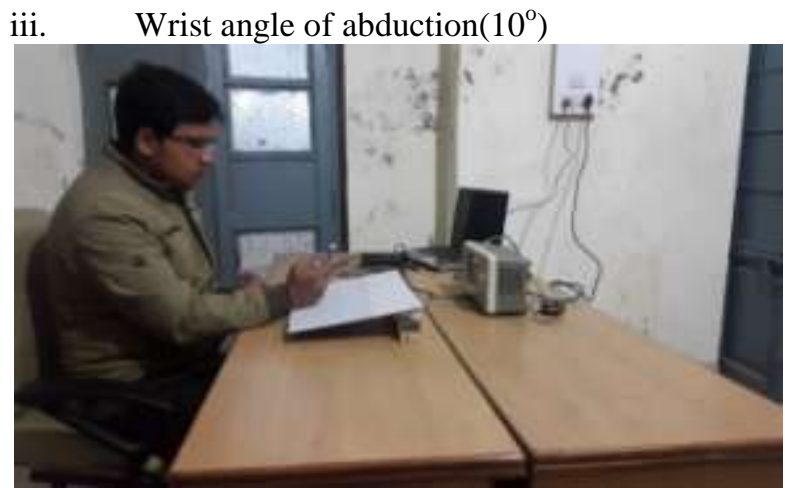

Figure-3.10 Experimental set up for $10^{\circ}$ wrist angle of abduction

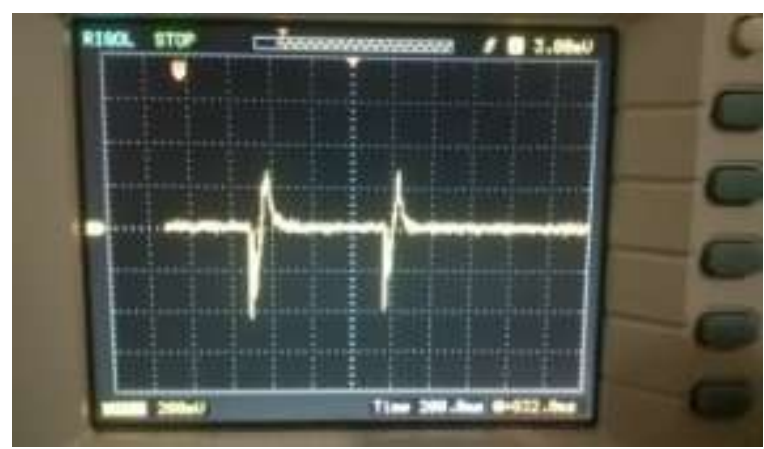

Figure- 3.11 Oscilloscope - Force applied on Y-axis and Response time on $\mathrm{X}$-axis 


\subsection{Procedure}

To evaluate the touch screen mobile phone users' performance in context with wrist angle of abduction for both one hand and two hand postures, experimental investigations were carried out as follows:

i. Vary the wrist angle of abduction by varying the inclination angle of mica plate and confirm the wrist abduction angle of subject by goniometer.

ii. Provide the touch screen mobile phone above the sensor point connected on the mica plate.

iii. Subject was asked to hold the mobile with the pre-defined posture for one hand and two hands and keep the finger on the reference point.

iv. Voice signal was given to each subject in terms of words "start and press the concerned icon".

v. As soon as the task was completed by pressing icon, the force applied and motor action time were recorded through the oscilloscope.

vi. The performance of each subject was recorded in terms of force applied and response time by changing the wrist abduction angle for three distinct tasks for both one hand and two hands postures.

vii. Each subject was imparted instructions so as to get complete familiarity with the tasks and posture for using touch screen mobile phone by one hand and two hand postures.

\subsection{Analysis}

The collected data through the experimental investigations as shown in tables 1 through 6 were analyzed by MANOVA (Multi Variate Analysis of Variance) using SPSS statistical software.

\section{EXPERIMENTATION AND RESULTS}

4.1 Experimental Observations

i. Touch screen mobile phone used by single hand

a. Wrist Angle of Abduction $\left(0^{\mathrm{O}}\right)$

Table 1 -Experimental observations for $0^{\circ}$ angle of abduction by single hand for three different tasks

\begin{tabular}{|c|c|c|}
\hline Subject & $\begin{array}{c}\text { Force applied } \\
\text { (mean) } \\
\text { (in milli-volts) }\end{array}$ & $\begin{array}{c}\text { Motor action } \\
\text { response time (mean) } \\
\text { (in milli-seconds) }\end{array}$ \\
\hline 1 & 546.6 & 520.0 \\
\hline 2 & 493.3 & 533.3 \\
\hline 3 & 440.0 & 453.3 \\
\hline 4 & 493.3 & 493.3 \\
\hline 5 & 480.0 & 533.3 \\
\hline 6 & 506.6 & 453.3 \\
\hline 7 & 466.6 & 533.3 \\
\hline 8 & 480.0 & 453.3 \\
\hline 9 & 480.0 & 480.0 \\
\hline 10 & 506.6 & 506.6 \\
\hline Mean & 489.3 & 496.0 \\
\hline
\end{tabular}

\section{b. Wrist Angle of Abduction ( $5^{\circ}$ )}

Table 2-Experimental observations for $5^{\circ}$ angle of abduction by single hand for three different tasks

\begin{tabular}{|c|c|c|}
\hline Subject & $\begin{array}{c}\text { Force applied } \\
\text { (mean) } \\
\text { (in milli-volts) }\end{array}$ & $\begin{array}{c}\text { Motor action response } \\
\text { time (mean) } \\
\text { (in milli-seconds) }\end{array}$ \\
\hline 1 & 520.0 & 493.3 \\
\hline 2 & 573.3 & 493.3 \\
\hline 3 & 493.3 & 546.6 \\
\hline 4 & 493.3 & 493.3 \\
\hline 5 & 520.0 & 546.6 \\
\hline 6 & 506.6 & 520.0 \\
\hline 7 & 493.3 & 506.6 \\
\hline 8 & 533.3 & 480.0 \\
\hline 9 & 533.3 & 546.6 \\
\hline 10 & 506.6 & 520.0 \\
\hline Mean & 517.3 & 514.6 \\
\hline
\end{tabular}

\section{c. Wrist Angle of Abduction (10 $\left.{ }^{\circ}\right)$}

Table 3-Experimental observations for 10 angle of abduction by single hand for three different tasks

\begin{tabular}{|c|c|c|}
\hline Subject & $\begin{array}{c}\text { Force applied } \\
\text { (mean) } \\
\text { (in milli-volts) }\end{array}$ & $\begin{array}{c}\text { Motor action response } \\
\text { time (mean) } \\
\text { (in milli-seconds) }\end{array}$ \\
\hline 1 & 493.3 & 626.6 \\
\hline 2 & 500.0 & 600.0 \\
\hline 3 & 640.0 & 560.0 \\
\hline 4 & 520.0 & 520.0 \\
\hline 5 & 413.3 & 533.3 \\
\hline 6 & 573.3 & 573.3 \\
\hline 7 & 493.3 & 466.6 \\
\hline 8 & 466.6 & 546.6 \\
\hline 9 & 600.0 & 493.3 \\
\hline 10 & 586.6 & 453.3 \\
\hline Mean & 528.6 & 537.3 \\
\hline
\end{tabular}

ii. Touch screen mobile phone used by two hands

a. Wrist Angle of Abduction $\left(0^{\circ}\right)$

Table 4-Experimental observations for $0^{\circ}$ angle of abduction by two hands for three different tasks

\begin{tabular}{|c|c|c|}
\hline Subject & $\begin{array}{c}\text { Force applied } \\
\text { (mean) } \\
\text { (in milli-volts) }\end{array}$ & $\begin{array}{c}\text { Motor action response time } \\
\text { (mean) } \\
\text { (in milli-seconds) }\end{array}$ \\
\hline 1 & 280.0 & 373.3 \\
\hline 2 & 226.6 & 320.0 \\
\hline 3 & 213.3 & 373.3 \\
\hline 4 & 240.0 & 293.3 \\
\hline 5 & 253.3 & 306.6 \\
\hline 6 & 240.0 & 320.0 \\
\hline 7 & 253.3 & 293.3 \\
\hline 8 & 186.6 & 306.6 \\
\hline 9 & 240.0 & 306.6 \\
\hline 10 & 240.0 & 306.6 \\
\hline Mean & 237.3 & 320.0 \\
\hline
\end{tabular}


b. Wrist Angle of Abduction ( $5^{\circ}$ )

Table 5-Experimental observations for $5^{\circ}$ angle of abduction by two hands for three different tasks

\begin{tabular}{|c|c|c|}
\hline Subject & $\begin{array}{c}\text { Force applied } \\
\text { (mean) } \\
\text { (in milli-volts) }\end{array}$ & $\begin{array}{c}\text { Motor action response } \\
\text { time (mean) } \\
\text { (in milli-seconds) }\end{array}$ \\
\hline 1 & 253.3 & 320.0 \\
\hline 2 & 293.3 & 360.0 \\
\hline 3 & 226.6 & 333.3 \\
\hline 4 & 253.3 & 346.6 \\
\hline 5 & 266.6 & 360.0 \\
\hline 6 & 253.3 & 320.0 \\
\hline 7 & 253.3 & 320.0 \\
\hline 8 & 240.0 & 346.6 \\
\hline 9 & 226.6 & 360.0 \\
\hline 10 & 266.6 & 400.0 \\
\hline Mean & 253.3 & 346.6 \\
\hline
\end{tabular}

c. Wrist Angle of Abduction $\left(\mathbf{1 0}^{\mathrm{O}}\right.$ )

Table 6-Experimental observations for $10^{\circ}$ angle of abduction by two hands for three different tasks

\begin{tabular}{|c|c|c|}
\hline Subject & $\begin{array}{c}\text { Force applied } \\
\text { (mean) } \\
\text { (in milli-volts) }\end{array}$ & $\begin{array}{c}\text { Motor action response } \\
\text { time (mean) } \\
\text { (in milli-seconds) }\end{array}$ \\
\hline 1 & 266.6 & 440.0 \\
\hline 2 & 226.6 & 400.0 \\
\hline 3 & 280.0 & 360.0 \\
\hline 4 & 293.3 & 346.6 \\
\hline 5 & 253.3 & 346.6 \\
\hline 6 & 320.0 & 400.0 \\
\hline 7 & 226.6 & 386.6 \\
\hline 8 & 280.0 & 413.3 \\
\hline 9 & 346.6 & 440.0 \\
\hline 10 & 280.0 & 360.0 \\
\hline Mean & 277.3 & 389.3 \\
\hline
\end{tabular}

\subsection{Results and Analysis}

The MANOVA (Multi Variate Analysis of Variance) is done to know the significant effect of angle of abduction for both single hand and two hands over force applied and reaction time while using the touch screen mobile phone. For analysis by MANOVA the force applied and response time is taken as response variables and the three independent tasks and conditions were selected as follows. The three fixed (independent) tasks were to press Bluetoooth, contacts, and settings icons on the touch screen mobile phone and the three conditions were the wrist angle of abductions $\left(0^{0}, 5^{0}\right.$ and $\left.10^{\circ}\right)$ for both single-hand and two hand while using touch screen mobile phone. The results are presented in tables 7 through 12 and in figures 4.1 through 4.4.

Table 7-Between-Subjects Factors

\begin{tabular}{|ll|l|}
\hline & & N \\
\hline Condition & 1_H_0 & 30 \\
& 1_H_10 & 30 \\
& 1_H_5 & 30 \\
2_H_0 & 30 \\
& 2_H_10 & 30 \\
2_H_5 & 30 \\
\hline
\end{tabular}

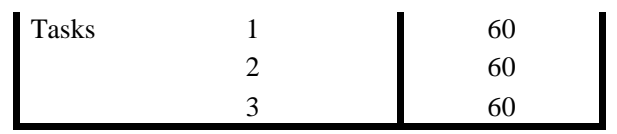

Table 8- Summary of MANOVA Tests of Between-Subjects Effects

\begin{tabular}{|c|c|c|c|c|c|c|}
\hline Source & $\begin{array}{l}\text { Depend } \\
\text { ent } \\
\text { Variabl } \\
\text { e }\end{array}$ & $\begin{array}{c}\text { Type III Sum } \\
\text { of Squares }\end{array}$ & df & $\begin{array}{c}\text { Mean } \\
\text { Square }\end{array}$ & $\mathrm{F}$ & Sig. \\
\hline \multirow[t]{2}{*}{$\begin{array}{l}\text { Corrected } \\
\text { Model }\end{array}$} & $\begin{array}{l}\text { Force_} \\
\text { applied }\end{array}$ & $4213317.778^{a}$ & 17 & $\begin{array}{r}247842 . \\
222\end{array}$ & 72.794 & .000 \\
\hline & $\begin{array}{l}\text { Reactio } \\
\text { n_time }\end{array}$ & $1680720.000^{\mathrm{b}}$ & 17 & $\begin{array}{r}98865.8 \\
82\end{array}$ & 40.282 & .000 \\
\hline \multirow[t]{2}{*}{ Intercept } & $\begin{array}{l}\text { Force_- } \\
\text { applied }\end{array}$ & 26526722.222 & 1 & $\begin{array}{r}265267 \\
22.222\end{array}$ & $\begin{array}{r}7791.2 \\
27\end{array}$ & .000 \\
\hline & $\begin{array}{l}\text { Reactio } \\
\text { n_time }\end{array}$ & 33904080.000 & 1 & $\begin{array}{r}339040 \\
80.000 \\
\end{array}$ & $\begin{array}{r}13814 . \\
037 \\
\end{array}$ & .000 \\
\hline \multirow[t]{2}{*}{$\begin{array}{l}\text { Conditio } \\
\mathrm{n}\end{array}$} & $\begin{array}{l}\text { Force_} \\
\text { applied }\end{array}$ & 2992917.778 & 5 & $\begin{array}{r}598583 . \\
556\end{array}$ & $\begin{array}{r}175.81 \\
1\end{array}$ & .000 \\
\hline & $\begin{array}{l}\text { Reactio } \\
\text { n_time }\end{array}$ & 1309413.333 & 5 & $\begin{array}{r}261882 . \\
667\end{array}$ & $\begin{array}{r}106.70 \\
3\end{array}$ & .000 \\
\hline \multirow[t]{2}{*}{ Case } & $\begin{array}{l}\text { Force_- } \\
\text { applied }\end{array}$ & 838751.111 & 2 & $\begin{array}{r}419375 . \\
556\end{array}$ & $\begin{array}{r}123.17 \\
6\end{array}$ & .000 \\
\hline & $\begin{array}{l}\text { Reactio } \\
\text { n_time }\end{array}$ & 331360.000 & 2 & $\begin{array}{r}165680 . \\
000\end{array}$ & 67.505 & .000 \\
\hline \multirow[t]{2}{*}{$\begin{array}{l}\text { Conditio } \\
\mathrm{n} * \text { Case }\end{array}$} & $\begin{array}{l}\text { Force_- } \\
\text { applied }\end{array}$ & 381648.889 & 10 & $\begin{array}{r}38164.8 \\
89\end{array}$ & 11.210 & \\
\hline & $\begin{array}{l}\text { Reactio } \\
\text { n_time }\end{array}$ & 39946.667 & 10 & $\begin{array}{r}3994.66 \\
7\end{array}$ & 1.628 & .103 \\
\hline \multirow[t]{2}{*}{ Error } & $\begin{array}{l}\text { Force_- } \\
\text { applied }\end{array}$ & 551560.000 & 162 & $\begin{array}{r}3404.69 \\
1\end{array}$ & & \\
\hline & $\begin{array}{l}\text { Reactio } \\
\text { n_time }\end{array}$ & 397600.000 & 162 & $\begin{array}{r}2454.32 \\
1\end{array}$ & & \\
\hline \multirow[t]{2}{*}{ Total } & $\begin{array}{l}\text { Force_- } \\
\text { applied }\end{array}$ & 31291600.000 & 180 & & & \\
\hline & $\begin{array}{l}\text { Reactio } \\
\text { n_time }\end{array}$ & 35982400.000 & 180 & & & \\
\hline \multirow[t]{2}{*}{$\begin{array}{l}\text { Corrected } \\
\text { Total }\end{array}$} & $\begin{array}{l}\text { Force_- } \\
\text { applied }\end{array}$ & 4764877.778 & 179 & & & \\
\hline & $\begin{array}{l}\text { Reactio } \\
\text { n_time }\end{array}$ & 2078320.000 & 179 & & & \\
\hline
\end{tabular}

a. $\mathrm{R}$ Squared $=.884$ (Adjusted R Squared $=.872$ )

b. R Squared $=.809$ (Adjusted R Squared $=.789$ )

\subsubsection{Profile plots}

i. Force applied

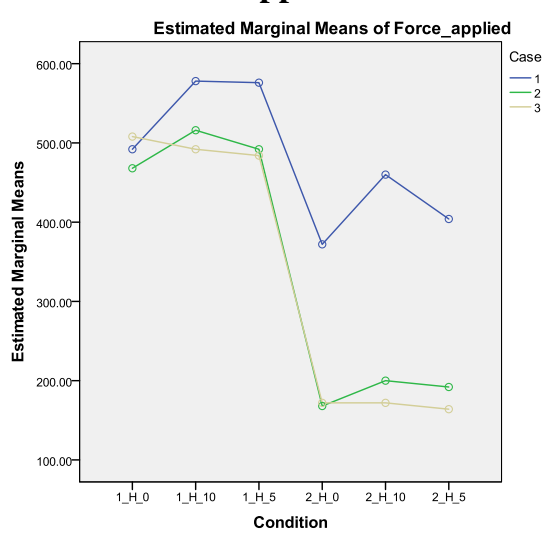

Figure 4.1- Line Diagram between the conditions for the force applied for three different tasks 


\section{ii. Reaction time}

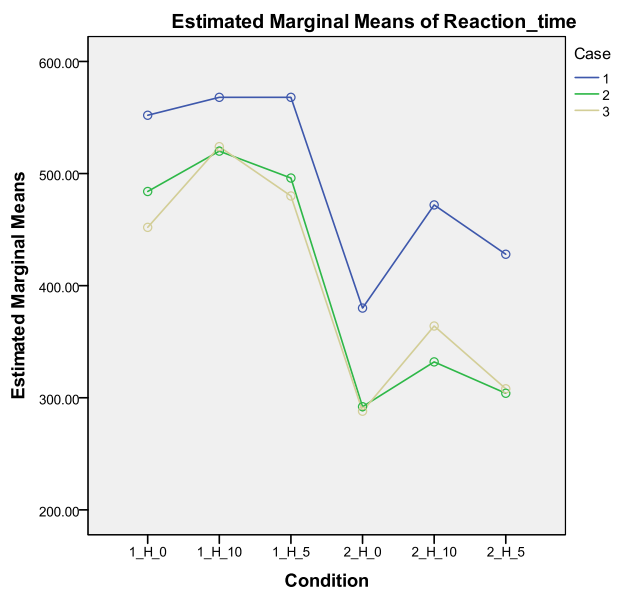

Figure 4.2- Line Diagram between the conditions for the response time for three different tasks

\subsubsection{Bar graphs}

\section{i. Applied force}

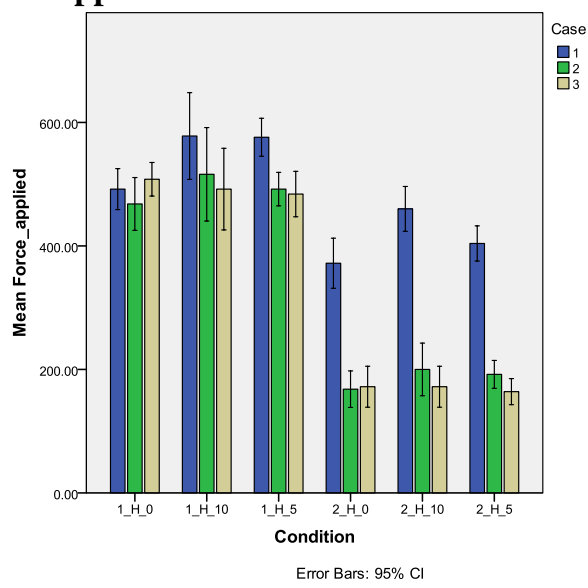

Figure 4.3- Bar graph between the conditions for the force applied for three different tasks

\section{ii. Reaction time}

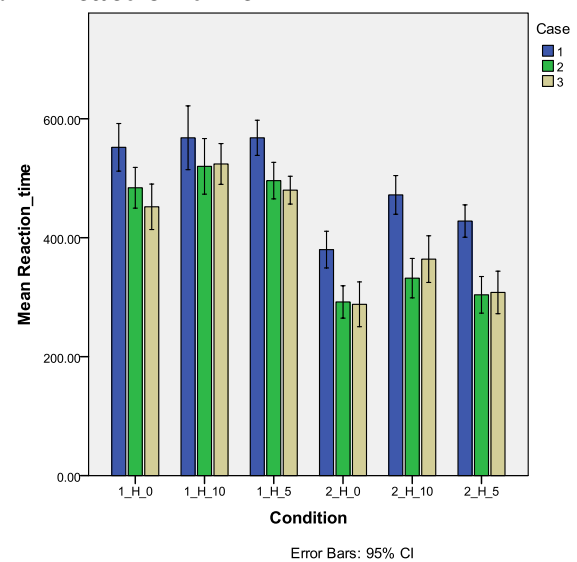

Figure 4.4- Bar graph between the conditions for the response time for three different tasks

\subsubsection{POST-HOC Tests}

i. Post- Hoc test between the conditions for the:

\section{a. Force applied}

Table 9-Post- Hoc test between the conditions for the force applied

\begin{tabular}{|c|c|c|c|c|c|c|}
\hline & \multirow{2}{*}{ Condition } & \multirow{2}{*}{$\mathrm{N}$} & \multicolumn{4}{|c|}{ Subset } \\
\hline & & & 1 & 2 & 3 & 4 \\
\hline \multirow{7}{*}{ Tukey HSD } & 2_H_0 & 30 & 237.3333 & & & \\
\hline & 2_H_5 & 30 & 253.3333 & & & \\
\hline & 2_H_10 & 30 & 277.3333 & & & \\
\hline & 1_H_0 & 30 & & 489.3333 & & \\
\hline & 1_H_5 & 30 & & 517.3333 & & \\
\hline & 1_H_10 & 30 & & 528.6667 & & \\
\hline & Sig. & & .090 & .101 & & \\
\hline
\end{tabular}

Means for groups in homogeneous subsets are displayed.

Based on observed means.

The error term is Mean Square (Error) $=3404.691$.

a. Uses Harmonic Mean Sample Size $=30.000$.

b. The group sizes are unequal. The harmonic mean of the group sizes is used. Type I error levels are not guaranteed.

c. Alpha $=.05$.

\section{b. Reaction time}

Table 10-Post - hoc test between the conditions for reaction time

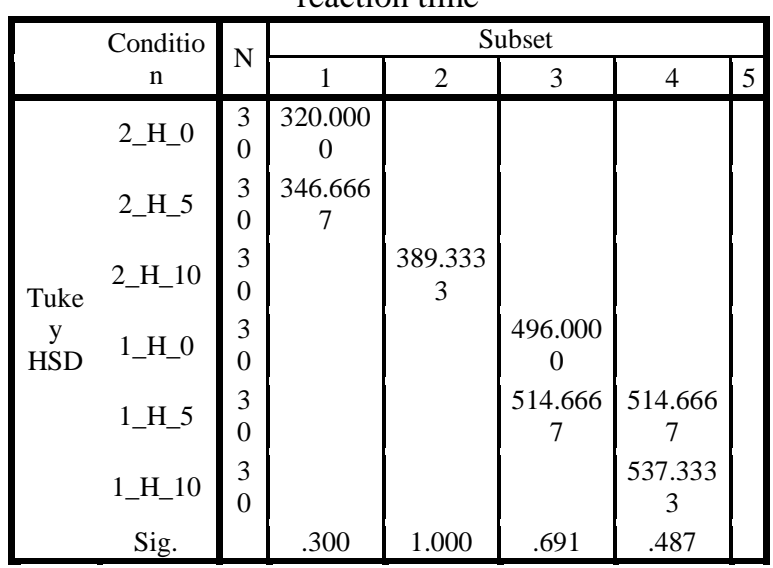

Means for groups in homogeneous subsets are displayed.

Based on observed means

The error term is Mean Square (Error) $=2454.321$.

a. Uses Harmonic Mean Sample Size $=30.000$.

b. The group sizes are unequal. The harmonic mean of the group sizes is used. Type I error levels are not guaranteed.

c. Alpha $=.05$. 
ii. a. Force applied

Table 11-Post- hoc test between the tasks for force applied

\begin{tabular}{|cc|c|c|c|}
\hline \multirow{4}{*}{ Tukks } & \multirow{2}{*}{$\mathrm{N}$} & \multicolumn{3}{|c|}{ Subset } \\
\cline { 4 - 5 } & & 60 & 332.0000 & 2 \\
\hline & 3 & 60 & 339.3333 & \\
& 2 & 60 & \\
& 1 & 60 & & 480.3333 \\
& Sig. & & .771 & 1.000 \\
\hline
\end{tabular}

Means for groups in homogeneous subsets are displayed.

Based on observed means.

The error term is Mean Square (Error) $=3404.691$.

a. Uses Harmonic Mean Sample Size $=60.000$.

b. The group sizes are unequal. The harmonic mean of the group sizes is used. Type I error levels are not guaranteed.

c. Alpha $=.05$.

\section{b. Reaction time}

Table 12-Post- hoc test between the tasks for the reaction time

\begin{tabular}{|cc|c|c|c|}
\hline \multirow{2}{*}{ Tasks } & \multirow{2}{*}{$\mathrm{N}$} & \multicolumn{3}{|c|}{ Subset } \\
\cline { 4 - 5 } & & & 1 & 2 \\
\hline & 3 & 60 & 402.6667 & \\
Tukey HSD & 2 & 60 & 404.6667 & \\
& 1 & 60 & & 494.6667 \\
& Sig. & & .973 & 1.000 \\
\hline
\end{tabular}

Means for groups in homogeneous subsets are displayed.

Based on observed means.

The error term is Mean Square (Error) $=2454.321$.

a. Uses Harmonic Mean Sample Size $=60.000$.

b. The group sizes are unequal. The harmonic mean of the group sizes is used. Type I error levels are not guaranteed.

c. Alpha $=.05$.

\subsubsection{Results from MANOVA (Multi Variate} Analysis of Variance) Test

- Angle of Abduction has significant effect over force applied and reaction time $(\mathrm{p}<0.05)$.

- Tasks have significant effect over force applied and reaction time $(\mathrm{p}<0.05)$.

- Interaction was found to be significant between angle of abduction and task for the dependent variable force applied. But there was no interaction found for the case of reaction time $(\mathrm{p}<0.05)$.

\subsubsection{Results from POST-HOC Test}

To further investigate where the significance lies for the angle of abduction and tasks over force applied and reaction time, Post-Hoc analysis was conducted (Tukey's Post-Doc Analysis). The following general conclusions are drawn:

- Two handed cases were significantly different from the single handed case; however the angle of abduction may be significant $(\mathrm{p}<0.05)$.

- Reaction time was significantly different for 0 and 10 degree angle of abduction for both the single handed and double handed conditions. $(\mathrm{p}<0.05)$.

- Task 1 was found to be significantly different from Task 2 and Task $3(\mathrm{p}<0.05)$.

\section{CONCLUSION}

Results obtained by experimental observations and analysis indicates that the touch screen mobile phone should be used by the mobile user by two hands at $0^{\circ}$ wrist angle of abduction for optimum performance, ergonomically. The less motor action response time will help the mobile user to response fast in an efficient manner and less applied force will give the less discomfort and more ergonomically correct posture and task execution while using the touch screen mobile phone. The results of this work can be directly applied to the practical field. By applying the correct posture, one can enhance the users' performance with less response time and less discomfort while using the touch screen mobile for longer hours of time.

Through the present experimental analysis and results, an attempt has been made to develop a better understanding of human performance in the context of using the touch screen mobile phone by using one hand and two hand postures at different wrist angle of abductions. One of the two studies explored the effect of wrist angle of abduction on two performance parameters that is, response time and force applied for both one hand and two hand postures. The second study explored the effect of three distinct tasks on two performance parameters response time and force applied.

On the basis of the results obtained, following concluding remarks were drawn:-

i. Wrist abduction angle have a significant effect over force applied and reaction time.

ii. Different tasks have significant effect over force applied and reaction time.

iii. Two handed posture was significantly different from the single handed posture for different wrist abduction angles used by the mobile users.

iv. For both the postures that is; single hand and two hands while using the touch screen mobile phone, the performance parameters, response 
time and force applied was found to be least for $0^{0}$ wrist angle of abduction.

v. For all the three distinct tasks, the least response time and force applied was found for the two hand posture for $0^{\circ}$ wrist angle of abduction.

vi. Analysis of results indicates that the touch screen mobile phone should be used by the mobile user by two hands at $0^{\circ}$ wrist angle of abduction for optimum performance, ergonomically. This will also help to reduce the musculoskeletal injuries in mobile phone users.

\section{REFERENCES}

[1]. Balakrishnan, V., Yeow, P.H.P., 2008. A study of the effect of thumb sizes on mobile phone texting satisfaction. J. Usability Stud. 3 (3), $118 \mathrm{e} 128$.

[2]. Carey, E., 2001. Effects of posture, force and rate of exertion at the wrist on discomfort and fatigue. Ph.D. Thesis. University of Limerick, Limerick, Republic of Ireland.

[3]. Ehrenstein, W.H., Schroeder-Heister, P., Heister, G., 1989. Spatial S-R compatibility with orthogonal stimulus-response relationship. Percep. Psychophys. 45 (3), $215 \mathrm{e} 220$.

[4]. Fitts, P.M., 1954. The information capacity of the human motor system in controlling the amplitude of movement. J. Exp. Psychol. 47 (6), 381e391.

[5]. Gold, J.E., Driban, J.B., Thomas, N., Chakravarty, T., Channell, V., Komaroff, E., 2012. Postures, typing strategies, and gender differences in mobile device usage: an observational study. Appl. Ergon. 43 (2), $408 \mathrm{e} 412$.

[6]. Khan I.A., Imadullah H., Khan S. and Adil A., 2016. Ergonomic Evaluation of the Angle of Abduction in Laptops Environment. International Journal of Engineering Research and Applications, 6(1), Version 4 : 01-08.

[7]. Khan I.A., 2014a. Multi-response ergonomic design of human-CNC machine interface. International Journal of Interactive Design and Manufacturing, 8(1): 13-31.

[8]. Khan I.A., 2014b. Multi-response ergonomic evaluation of female CNC machine operators. International Journal of Human Factors and Ergonomics, 3(1) : 32-64.

[9]. Khan I.A., 2014c. Multi-Response Ergonomic Evaluation of Higher Age Group CNC Machine Operators. International Journal of Engineering Research and Applications, 4(8), Version $7: 01-21$.

[10]. Khan I.A., 2014d. Multi-Response Ergonomic Analysis of Middle Age Group CNC Machine Operators. International Journal of Science, Technology and Society, 2(5): 133-151.
[11]. Khan I.A., 2012. Ergonomic design of human-CNC machine interface", Inaki Maurtua, Editor, Human Machine InteractionGetting Closer, InTech Open Access Publisher, Croatia, pages 115 - 136.

[12]. Khan I.A. and Asghar M., 2010. Ergonomic evaluation of the angle of abduction in a computer numerically controlled-electro discharge machine environment. International Journal of Cognition Technology \& Work, 12(4):263-269.

[13]. Khan I.A. and Asghar M., 2011. Ergonomic design of the viewing angle in a computer numerically controlled-electro discharge machine environment", W. Karwowski, G. Salvendy, Editors, Advances in Human Factors, Ergonomics and Safety in Manufacturing and Service Industries, CRC Press, Taylor \& Francis Group, New York, pages 169-179.

[14]. Jacob O. Wobbrock, Brad A. Myers, 2008, "The performance of hand postures in frontand back-of-device interaction for mobile computing", Int. J. Human-Computer Studies 66 (2008), 857-875.

[15]. Liang, H., Hwang, Y., Chang, F., 2009. Effects of input methods on inter-key press intervals during continuous typing. Ergonomics 52 (9), 1153e1161 (Taylor \& Francis).

[16]. Lyons, K., Starner, T., Plaisted, D., Fusia, J., Lyons, A., Drew, A., Looney, E.W., 2004. Twiddler typing: one-handed chording text entry for mobile phones. In: Proceedings of the SIGCHI Conference on Human Factors in Computing Systems, pp. 671e678(Vienna, Austria).

[17]. Lyons, K., Starner, T., Gane, B., 2006. Experimental evaluations of the twiddler onehanded chording mobile keyboard. Human-Computer. Interact. 21 (4), 343e392.

[18]. MacKenzie, I.S., 2002. KSPC (Keystrokes per Character) as a characteristic of text entry techniques. In: Mobile HCI '02 Proceedings of the 4th International Symposium on Mobile Human-computer Interaction, pp. $195 \mathrm{e} 210$.

[19]. MacKenzie, I.S., Lopez, M., Castelluci, S., 2009. Text entry with the Apple iPhone and the Nintendo Wii. In: Proceedings of ACM CHI 2009 Conference on Human Factors in Computing Systems. Presented at the Proceedings of ACM CHI Conference on Human Factors in Computing Systems.

[20]. Paul C LaSteyo, Donna L Wheeler, 1994," Reliability of Passive Wrist Flexion and Extension Goniometric Measurements: A 
Multicenter Study", Research report, 1994; 74:162-174

[21]. Taeil Kim, Eui S. Jung, Youngjae Im, 2013. "Optimal control location for the customeroriented design of smart phones". Department of Industrial Management Engineering, Korea University. Republic of Korea.

[22]. Wigdor, D.J., 2004. Chording and Tilting for Rapid, Unambiguous Text Entry to Mobile Phones (Ph.D. Dissertation). University of Toronto, pp. 1e73. 